\title{
A Mathematical Approach to Predicting Biological Values from Ruminal pH Measurements
}

\author{
O. AlZahal, E. Kebreab, J. France, and B. W. McBride ${ }^{1}$ \\ Centre for Nutrition Modelling, Department of Animal and Poultry Science, University of Guelph, Guelph, Ontario, Canada N1G 2W1
}

\begin{abstract}
The use of continuous recording to monitor ruminal $\mathrm{pH}$ has received growing attention. Continuous ruminal $\mathrm{pH}$ data are usually summarized for each 24 -h period for each cow by calculating mean $\mathrm{pH}$, maximum $\mathrm{pH}$, minimum $\mathrm{pH}$, amount of time $(\mathrm{min} / \mathrm{d})$ below $\mathrm{pH} 5.6$ and 6.0, and area (time $\times \mathrm{pH}$ ) below $\mathrm{pH} 5.6$ and 6.0. In this study, a novel approach to analyzing ruminal $\mathrm{pH}$ is introduced. A database from 6 published studies encompassing 8 trials and 13 different treatment groups was used in a meta-analysis. Trials were selected on their ability to obtain daily $\mathrm{pH}$ measurements and diet analyses. A total of 613 records met the criteria for inclusion in the meta-analysis. The database was subdivided based on nonfiber carbohydrate (NFC, \% of dry matter) level in the diet into low (32 to $36 \%, \mathrm{n}=105$ ), moderate (37 to $39 \%, \mathrm{n}=326)$, and high $\mathrm{NFC}(>40 \%, \mathrm{n}=159)$. From each day of recording and for each cow, the amount of time below multiple $\mathrm{pH}$ points from 5.0 to 7.6 using a 0.2 -unit $\mathrm{pH}$ interval (i.e., 5.0, 5.2, ...., and 7.6) was calculated. Sigmoidal curves were constructed to summarize daily ruminal $\mathrm{pH}$ records using calculated time below $(\mathrm{min} / \mathrm{d})$ as the $y$-variate and $\mathrm{pH}$ cutoff point as the $x$-variate. The objectives of this study were to 1) collate continuously recorded ruminal $\mathrm{pH}$ data from studies that used a dietary regimen to induce $\mathrm{pH}$ depression, 2) assess mathematical equations and subject the collated data to analysis, 3) determine the most suitable equation or equations to describe the data, and 4) derive values from the selected equation or equations that may have biological implication across dietary treatments. The analysis was performed on pooled data in each category using nonlinear modeling. Trial effect was considered as fixed and also as random. Four growth functions were considered: spline lines, Morgan, Richards, and logistic. All models had 4 parameters except the logistic equation, which had 3 . The logistic and the Richards equations gave a better fit
\end{abstract}

Received August 15, 2006.

Accepted March 30, 2007.

${ }^{1}$ Corresponding author: bmcbride@uoguelph.ca to the data than did the Morgan and spline lines. All parameter estimates were significant except for 1 parameter for the spline lines. The logistic equation uses the least number of parameters and consistently gave a better prediction. Therefore, the logistic is considered the best option to use in describing $\mathrm{pH}$ curves. Modelderived values that have biological interpretation such as curve inflection point, curve slope, and time and area below pH 5.6 and 6.0 were calculated for all models. Diets with higher NFC content resulted in greater depression in ruminal $\mathrm{pH}$. Degree of drop in $\mathrm{pH}$ can be described by a shift of $\mathrm{pH}$ curve position toward the lower $\mathrm{pH}$ range, hence, by greater values of predicted time and area below most critical pH cut-off points. This shift can also be identified by a decrease in curve inflection point and curve slope. Therefore, we suggest using these model-derived biological values to summarize continuously recorded $\mathrm{pH}$ data. For example, the inflection points for high, moderate, and low NFC levels were 1.01, 1.17, and 1.28; respectively. This approach permits comparison of $\mathrm{pH}$ data across studies and helps quantify dietary effects on ruminal $\mathrm{pH}$.

Key words: ruminal $\mathrm{pH}$, continuous recording, logistic equation, nonfiber carbohydrate

\section{INTRODUCTION}

Ruminal $\mathrm{pH}$ depression caused by overfeeding of grains to meet requirements of cows during early lactation may lead to subacute ruminal acidosis (SARA). Determination of ruminal $\mathrm{pH}$ is considered the best method to diagnose this disorder. However, variation in $\mathrm{pH}$ measurement methods and interpretation thereof have contributed to inconsistency within the literature. Methods used to measure $\mathrm{pH}$ include rumenocentesis, oral stomach tubing, and rumen cannulation. Nordlund and Garrett (1994) suggested $\mathrm{pH}$ values of 5.2 and 5.6 as the critical points for diagnosis of acute and subacute ruminal acidosis, respectively. They suggested that samples obtained by rumenocentesis should be collected from a representative group of animals 5 to $8 \mathrm{~h}$ postfeeding in TMR-fed herds or 2 to $5 \mathrm{~h}$ postfeeding in component-fed herds. The use of continuously acquired ruminal $\mathrm{pH}$ data provides more frequent data points 
Table 1. List of previously published studies included in the meta-analysis ${ }^{1}$

\begin{tabular}{lccccc}
\hline & & Treatment \\
Study & Trial & groups, $n$ & Low & Moderate & High \\
\hline Keunen et al., 2002 & 1 & 2 & $35.5(40)$ & & $43.6(38)$ \\
& 2 & 2 & $33.0(20)$ & & $41.9(18)$ \\
Mutsvangwa et al., 2002 & 1 & 1 & & $38.4(105)$ & \\
Keunen et al., 2003 & 2 & 1 & & $38.8(94)$ & $45.4(56)$ \\
Osborne et al., 2004 & & 2 & & $37.0(60)$ & \\
Cottee et al., 2004 & & 2 & $32.8(56)$ & & \\
Rustomo et al., 2006a & & 2 & $35.3(12)$ & $38.6(12)$ & \\
\hline
\end{tabular}

\footnotetext{
${ }^{1}$ The number of continuous acquisition records (d) meeting the criteria for inclusion in the meta-analysis for each treatment group is given in parentheses.

${ }^{2} \mathrm{NFC}$ level in the diet: low, 32 to $36 \%$; moderate, 37 to $39 \%$; and high, $>40 \% \mathrm{DM}$.
}

that permit the assessment of diurnal fluctuation of ruminal $\mathrm{pH}$ in relation to dietary regimen (Keunen et al., 2002). However, continuous recording systems are presently considered technically and economically prohibitive. Thus, the development of user-friendly and relatively cheaper systems is expected to spread the use of continuously recorded ruminal $\mathrm{pH}$ (AlZahal et al., 2007; Krause et al., 2005; Penner et al., 2006). Continuous recording has enabled researchers to measure the amount of time spent below a critical $\mathrm{pH}$ point, which has added further complexity to the interpretation of ruminal $\mathrm{pH}$ data. Keunen et al. (2002) computed time below pH 5.6 and 5.8 to define SARA, whereas Krause and Combs (2003) used 5.8. Rustomo et al. (2006a,b) suggested using a wider range of $\mathrm{pH}$ points on a continuous scale from $\mathrm{pH} 5.0$ to 7.2. None of these studies defined $\mathrm{pH}$ depression as the minimum amount of time spent below a critical $\mathrm{pH}$ point or suggested a methodology that permits integration of studies to define ruminal $\mathrm{pH}$ depression. Therefore, the objectives of this study were to 1) collate continuously recorded ruminal $\mathrm{pH}$ data from studies that used dietary regimens to induce $\mathrm{pH}$ depression; 2) select mathematical equations and analyze collated data; 3 ) determine the most suitable equation or equations that describe the data; and 4) derive values from selected equations that may aid in defining biological measures across dietary treatments.

\section{MATERIALS AND METHODS}

\section{Data Sources}

A database obtained from 6 published studies comprising 8 trials and 13 different treatment groups was used in the analysis (Table 1). Trials were selected based on the following criteria: 1) there was nutritionally induced ruminal $\mathrm{pH}$ depression, 2) ruminal $\mathrm{pH}$ was continuously recorded, 3) daily $\mathrm{pH}$ records were available, and 4) studies reported chemical analysis of the diet and DM intake for each treatment group. All 6 published studies used in this analysis were conducted at the same facility (Physiology Wing of the Elora Dairy Research Centre, Elora, Ontario, Canada) between 1999 and 2005. The studies used the nutritional model described by Keunen et al. (2002) to induce ruminal $\mathrm{pH}$ depression, with the exception of the study of Rustomo et al. (2006a). Briefly, animals were fed a TMR twice a day at 0700 and $1300 \mathrm{~h}$ during wk 1 . During wk 2, a portion of the offered TMR [25\% in Keunen et al. (2002), Keunen et al. (2003), and Cottee et al. (2004); $15 \%$ in Mutsvangwa et al. (2002) and Osborne et al. (2004) on a DM basis] was replaced with mixed-grain pellets (50:50, wheat:barley) that were fed in multiple meals throughout the day. Rustomo et al. (2006a) induced ruminal $\mathrm{pH}$ depression by feeding a high-acidogenic-value (HAV) diet as a TMR twice a day at 0900 and $1300 \mathrm{~h}$. The acidogenic value (AV) concept was first introduced by Wadhwa et al. (2001) to evaluate acid production from feedstuffs by measuring Ca dissociation from $\mathrm{CaCO}_{3}$. Rustomo et al. (2006c) ranked common feedstuffs used in Ontario, Canada, based on AV. In subsequent studies (Rustomo et al., 2006a,b), high $\mathrm{AV}$ and low AV feedstuffs were used to formulate 2 distinct diets with high and low $\mathrm{AV}(\mathbf{L A V})$, respectively, to study the effect of acid load and its interaction with particle size on in vivo ruminal $\mathrm{pH}$. All studies used in the meta-analysis employed the same continuous recording system (Keunen et al., 2002) to measure ruminal $\mathrm{pH}$, and $\mathrm{pH}$ was recorded every minute for 3 to $5 \mathrm{~d}$ during the treatment week following $1 \mathrm{wk}$ of dietary adaptation.

Daily $\mathrm{pH}$ records were examined individually, outliers were omitted ( $\mathrm{pH}<4$ or $\mathrm{pH}>7.6$ ), and only records that contained $\geq 1,200$ data points (approximately $20 \mathrm{~h} /$ $\mathrm{d}$ of recording time) were included in the analysis. As a result, 613 records met the criteria for inclusion in the meta-analysis. The database was divided based on 
Cut-off point (pH)

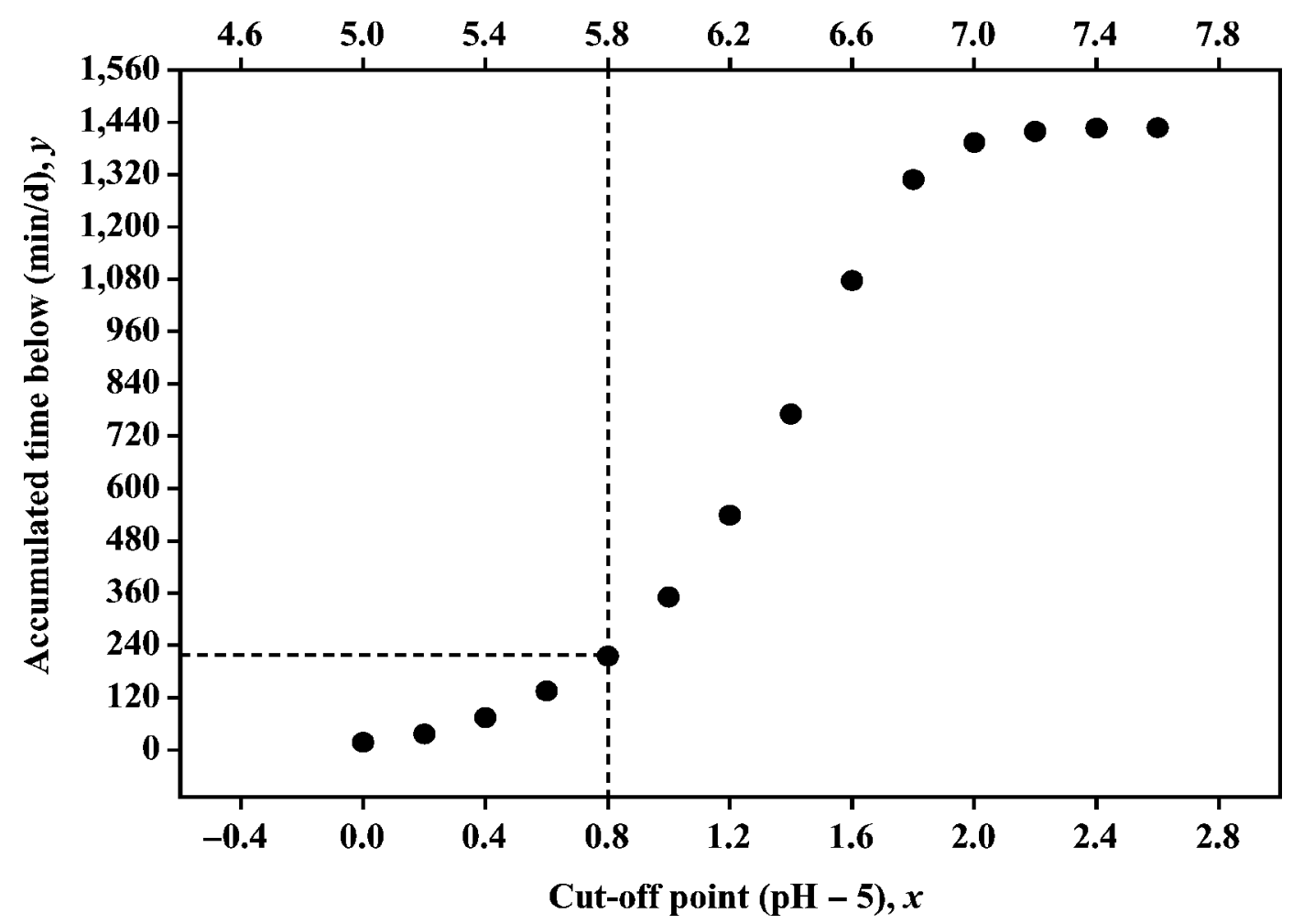

Figure 1. An example of a constructed $\mathrm{pH}$ curve for one of the continuous $\mathrm{pH}$ daily records. The symbol (@) represents accumulated time below ( $y$-axis, min/d) a $\mathrm{pH}$ cut-off point (top $x$-axis). The bottom $x$-axis represents $\mathrm{pH}-5$; thus, 0 was considered as the starting point when fitting candidate functions. The dotted lines indicate the time spent ( $215 \mathrm{~min})$ below $\mathrm{pH} 5.8$ during that day.

dietary level of $\mathrm{NFC}(\%$ of $\mathrm{DM})$ into low (32 to $36 \%, \mathrm{n}=$ 105 ), moderate (37 to $39 \%, \mathrm{n}=326$ ), and high $\mathrm{NFC}$ $(>40 \%, \mathrm{n}=159$; Table 1$)$. Amount of accumulated time $(\mathrm{min} / \mathrm{d})$ spent below each $\mathrm{pH}$ cut-off point $(5.0,5.2, \ldots$, 7.6) was calculated for each $\mathrm{pH}$ record in the database. Accumulated time spent below ( $y$-variate, 0 to 1,440 $\mathrm{min} / \mathrm{d}$ ) was plotted against the range of the $\mathrm{pH}$ cut-off points ( $x$-variate, $\mathrm{pH} 5$ to 7.6) for each daily $\mathrm{pH}$ record to generate a sigmoidal shape (Figure 1) that will be referred to as a "pH curve" throughout this article. $\mathrm{pH}$ curves for each level of NFC were fitted to candidate functions. The sigmoidal curves represent the relationship between ruminal $\mathrm{pH}$ and dietary NFC taking into account accumulated times spent below $14 \mathrm{pH}$ cut-off points rather than just the few cut-off points that are used in conventional approaches; for example, $\mathrm{pH} 5.6$ and 5.8. Because all functions fitted were growth functions, $\mathrm{pH}$ minus 5 was considered the starting point on the $x$-axis, and a small positive value of $10^{-10}$ was used instead of zero as a starting point on the $y$-axis when applicable (Figure 1).

Nonfiber carbohydrate contents were calculated as follows:

$$
\mathrm{NFC}=100-(\mathrm{CP}+\mathrm{NDF}+\mathrm{E})
$$

where $\mathrm{E}$ is the average content of ash and fat; $\mathrm{E}$ equals 10, 10.4, and 4.7 for mixed feed, mixed hay, and grain mix, respectively, in this region of Ontario (Agri-Food Laboratories, Guelph, Ontario, Canada).

\section{Candidate Functions}

The 4 equations used to describe $\mathrm{pH}$ curves are presented in Table 2. For more details, refer to chapter 5 of Thornley and France (2007). The 4 equations were growth functions that have been used to describe growth of animals and plants. The first equation, spline lines, is a simple 4-parameter model $\left(y_{0}, y_{f}, x_{0}\right.$, and $\left.x_{f}\right)$. The spline lines equation is a piecewise-linear equation that fits the data with 3 straight lines. The second equation, Morgan, is also a 4-parameter function $y_{0}, y_{f}, x_{h}$, and $n$ ). The parameter $x_{h}$ refers to the $\mathrm{pH}$ cut-off point under which the animal spent half of the day. The third equation, logistic, has the least number of parameters $\left(y_{0}, y_{f}\right.$, and $\left.k\right)$. The fourth equation, Richards, has an extra parameter, $n$. The Richards equation encom- 
Table 2. Equations used to describe ruminal $\mathrm{pH}$ curves

\begin{tabular}{|c|c|c|}
\hline Equation & Functional form $^{1}$ & Inflection point $\left(x^{*}, y^{*}\right)$ \\
\hline Spline lines & $\begin{array}{l}y(x)=y_{0}, 0 \leq x \leq x_{0} \\
y(x)=y_{0}+k\left(x-x_{0}\right), x_{0}<x<x_{f} \\
y(x)=y_{f}, x \geq x_{f} \\
k=\frac{y_{f}-y_{0}}{x_{f}-x_{0}}\end{array}$ & Not applicable \\
\hline Morgan & $y(x)=\frac{y_{0} x_{h}^{n}+y_{f} x^{n}}{x_{h}^{n}+x^{n}}$ & $\begin{array}{l}x^{*}=x_{h}\left(\frac{n-1}{n+1}\right)^{1 / n} \\
y^{*}=\frac{(1+1 / n) y_{0}+(1-1 / n) y_{f}}{2} \\
n \geq 1\end{array}$ \\
\hline Logistic & $y(x)=\frac{y_{0} y_{f}}{\left[y_{0}+\left(y_{f}-y_{0}\right) \mathrm{e}^{-k x}\right]}$ & $\begin{aligned} x^{*} & =\frac{1}{k} \ln \left(\frac{y_{f}-y_{0}}{y_{0}}\right) \\
y^{*} & =\frac{1}{2} y_{f}\end{aligned}$ \\
\hline Richards & $y(x)=\frac{y_{0} y_{f}}{\left[y_{0}^{n}+\left(y_{f}^{n}-y_{0}^{n}\right) \mathrm{e}^{-k x}\right]^{1 / n}}$ & $\begin{array}{l}x^{*}=\frac{1}{k} \ln \left(\frac{y_{f}^{n}-y_{0}^{n}}{n y_{0}^{n}}\right) \\
y^{*}=y_{f}\left(\frac{1}{n+1}\right)^{1 / n} \\
n>-1\end{array}$ \\
\hline
\end{tabular}

${ }^{1} y(x)=$ time spent below cut-off point $x(\mathrm{~min} / \mathrm{d}), x=\mathrm{pH}-5$, and $y_{0}, y_{f}, x_{0}, x_{f}, x_{h}, k$ (all $>0$ except $n>-1$ in the case of Richards) are parameters that define the scale and shape of the curves.

passes the Gompertz, logistic, and monomolecular (diminishing returns) equations when $n$ has a value of 1 , 0 and -1 , respectively.

\section{Biological Values}

Values that possess biological interpretation were derived from the models. The predicted values were intended to provide a numerical differentiation of $\mathrm{pH}$ curves. Biological values predicted from models accounted for the trial effect. Point of inflection (IP) of a $\mathrm{pH}$ curve, the point at which a curve changes direction from acceleration to deceleration, was calculated as given in Table 2. Average slope of the $\mathrm{pH}$ curve between 2 given points about IP for Morgan, logistic, and Richards was calculated as follows:

$$
\Delta=\frac{y\left(x_{2}\right)-y\left(x_{1}\right)}{x_{2}-x_{1}}
$$

where $x_{1}=\mathrm{IP}-0.4$ and $x_{2}=\mathrm{IP}+0.4$.

The slope for spline lines was equal to $k$ (Table 2). Models could predict time spent below any $\mathrm{pH}$ cut-off point and area under the curve (AUC), taking into account the trial effect. The AUC between 2 points, $x_{3}$ and $x_{3}+\delta$, was calculated as follows:

$$
\mathrm{AUC}=\int_{x_{3}}^{x_{3}+\delta} y(x) \mathrm{d} x, \text { where } x=\mathrm{pH}-5
$$

\section{Statistical Analysis}

The data were pooled by each NFC category, and statistical analyses were performed using the nonlinear mixed procedure (PROC NLMIXED; v. 9.1; SAS Institute, 2004). Trial effect was considered not only as fixed but also as random because the data came from different trials. Model performance was evaluated using the significance level of the parameters estimated, variance of error estimate, and its standard error. Bayesian information criteria (BIC; Leonard and Hsu, 2001) were used to compare models. Bayesian information criteria are model-order selection criteria based on parsimony; BIC favor simpler models by imposing penalty on models that include additional parameters. Bayesian information criteria combine both maximum likelihood and (log) maximum likelihood penalized with a term related to model complexity as follows:

$$
\mathrm{BIC}=-2 \log (\hat{J})+K \log (N)
$$

where $\hat{J}$ is the maximum likelihood, $K$ is the number of independent parameters in the model, and $N$ is the 
sample size. When comparing models, a smaller numerical value of BIC indicates a better fit. Accuracy of models was assessed by computing the mean square prediction error (MSPE; Bibby and Toutenburg, 1977):

$$
\operatorname{MSPE}=\frac{1}{M} \sum_{i=1}^{M}\left(P_{i}-A_{i}\right)^{2},
$$

where $i=1,2, \ldots M, M$ is the number of pairs of modelpredicted and actual (observed) values being compared and $P_{i}$ and $A_{i}$ are the $i$ th model-predicted and actual values; respectively. The MSPE has limitation in assessing model performance in that it removes the negative sign and weighs the deviations by their squares, yielding more influence to larger deviations (Mitchell and Sheehy, 1997). Comparisons of model accuracy were based on the root of MSPE (RMSPE) and RMSPE as a percentage of the observed mean (\%RMSPE). Mean square prediction error was decomposed into error due to overall bias of prediction, error due to deviation of the regression slope from unity, and error due to disturbance or random variation (Bibby and Toutenburg, 1977). Concordance correlation coefficient (Lin, 1989) was used to assess model precision and accuracy. The first component is the correlation coefficient $(r)$ that measures precision. The second component $\left(\boldsymbol{C}_{\boldsymbol{b}}\right)$ is the bias correction factor that assesses model accuracy. If $C_{b}$ equals 1 , this indicates that no deviation from a $45^{\circ}$ slope had occurred. The multiplication of both values gives both precision and accuracy at the same time. A $t$-test was performed to determine whether biological values calculated across functions for each level of NFC were similar, and also to determine whether biological values predicted using the same model were different across levels of NFC.

\section{RESULTS AND DISCUSSION}

Figures 2 and 3 show the fit of each model to the $\mathrm{pH}$ data. Table 3 summarizes the key statistical measures used to compare performance of the models. Each model was evaluated separately for low, moderate and high levels of NFC. All models for all levels of NFC gave similar variance of error. For low and moderate levels of NFC, all models had significant parameter estimates and the Richards equation gave the lowest BIC followed by the logistic, spline lines, and Morgan equations. For high NFC level, all parameter estimates were significant except for 1 parameter estimate for the spline lines. The BIC value was the lowest for the spline lines followed by Richards, logistic, and Morgan equations. For low and moderate NFC, the logistic equation gave the lowest values for RMSPE and \%RMSPE, whereas the Richards model gave the lowest values for RMSPE
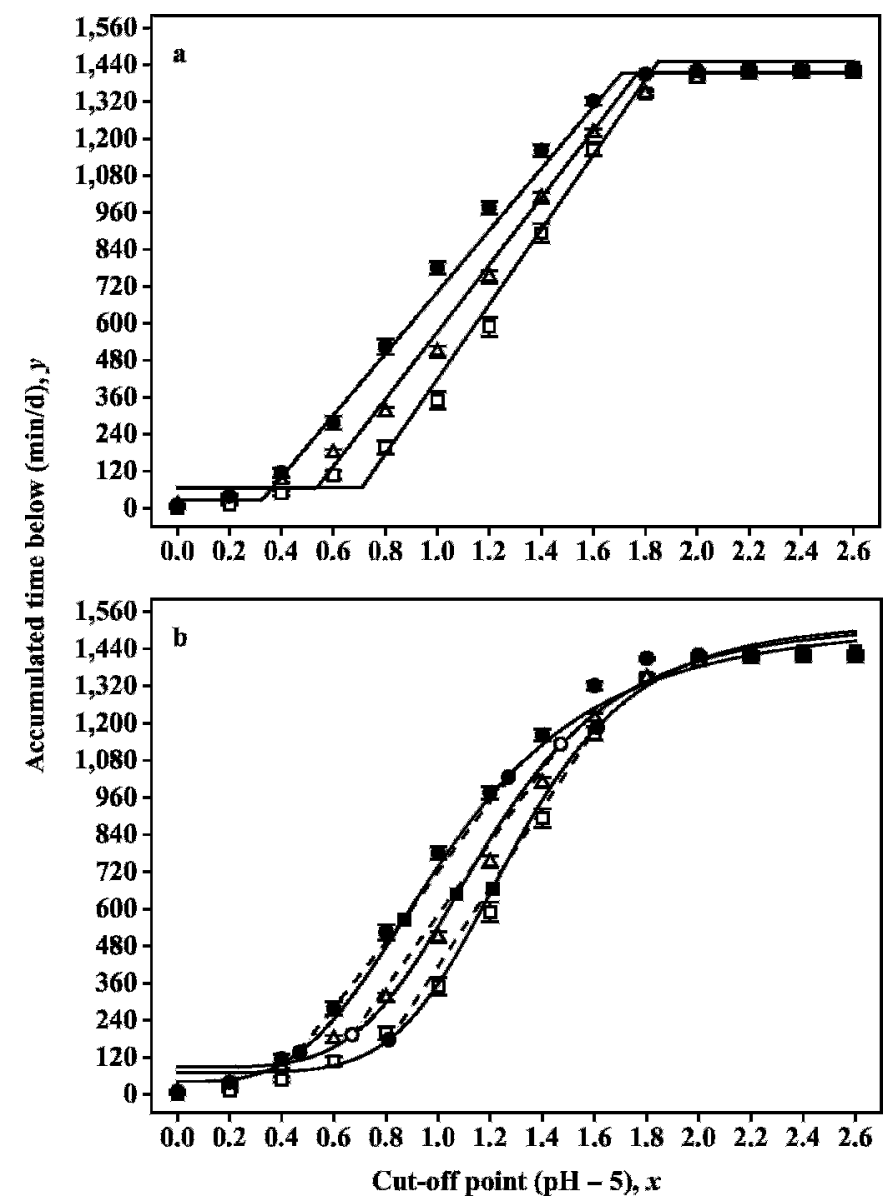

Figure 2. pH curves for low, moderate, and high levels of dietary NFC level (\%, DM basis). The $y$-axis represents the accumulated time $(\mathrm{min} / \mathrm{d})$ spent below each corresponding $\mathrm{pH}$ cut-off point on the $x$ axis. The scale from 0 to 2.6 on the $x$-axis represents $\mathrm{pH} 5$ to 7.6. Symbols indicate average observed values for low NFC ( $\square$ ), moderate NFC $(\triangle)$, high NFC $(\bullet)$, and point of inflection (ם). Lines were obtained by fitting candidate functions: spline lines (a) and Morgan (b). Dashed lines $(----)$ represent slopes of $\mathrm{pH}$ curves. Error bars represent $\mathrm{SE}$ of the mean of observed values $(\mathrm{n}=128,326$, and 159 ; respectively).

and \%RMSPE for high NFC (Table 4). Despite the fact that MSPE was small for the Richards model, decomposition of MSPE especially for low and moderate NFC, showed greater mean bias and smaller random error. This was caused by the Richards equation slightly but consistently overpredicting values, which in turn caused a significant difference between the predicted and observed means. However, concordance correlation coefficient values were $>0.99$ for all models (data not shown), which indicated high precision and accuracy. The logistic and Richards equations gave a better fit to the data than the Morgan and spline lines. Although Richards gave a slightly better fit than the logistic, it proved to be an overparameterized model. Therefore, 


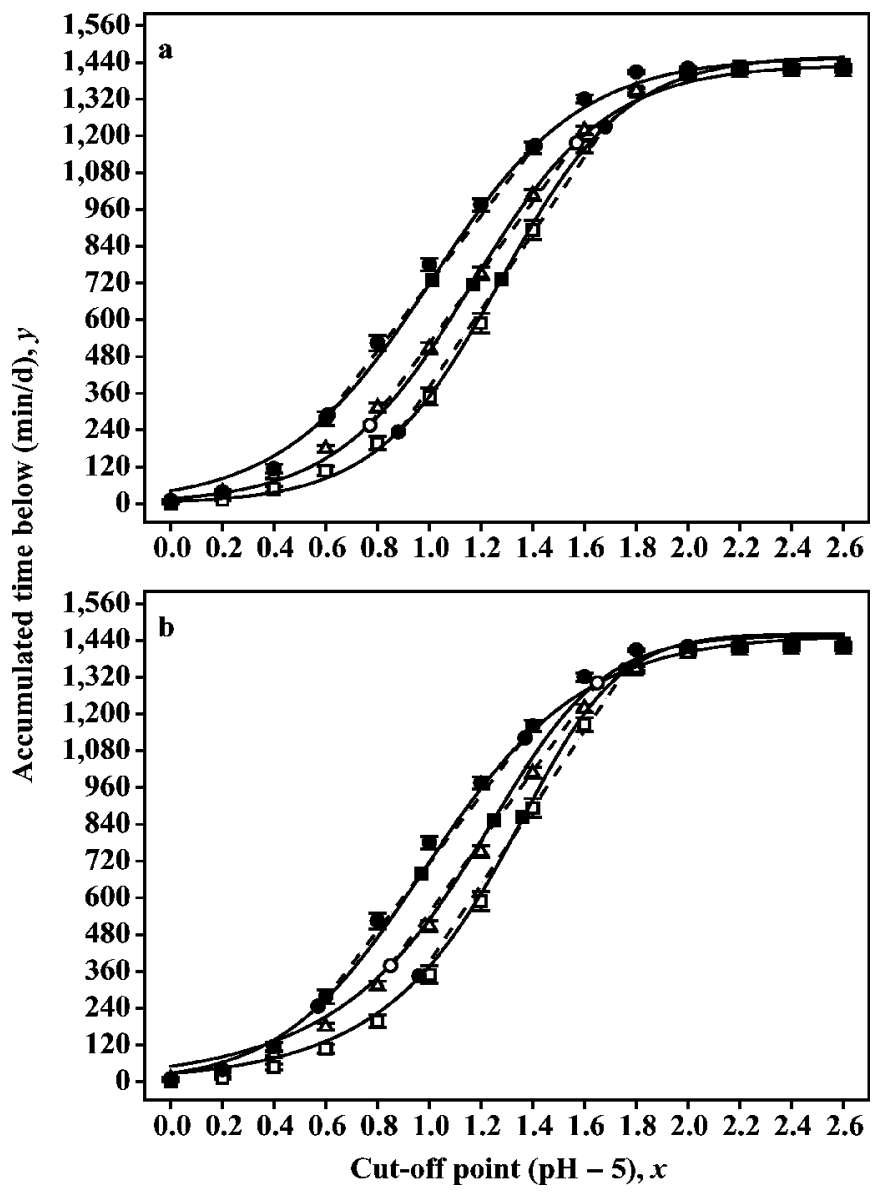

Figure 3. $\mathrm{pH}$ curves for low, moderate, and high levels of dietary NFC (\%,DM basis). The $y$-axis represents the accumulated time (min/ d) spent below each corresponding $\mathrm{pH}$ cut-off point on the $x$-axis. The value 0 to 2.6 on the $x$-axis represents pH 5 to 7.6. Symbols indicate average observed values for low $\mathrm{NFC}(\square)$, moderate NFC $(\triangle)$, high NFC (-), and point of inflection (ם). Lines were obtained by fitting candidate functions: logistic (a) and Richards (b). Dashed lines $(----)$ represent slopes of $\mathrm{pH}$ curves. Error bars represent $\mathrm{SE}$ of the mean of observed values $(\mathrm{n}=128,326$, and 159 ; respectively).

the logistic was considered the optimal choice to use in describing $\mathrm{pH}$ curves.

Table 5 summarizes biological values derived using the models. The values calculated within each level of NFC using different models were significantly different. Slopes and IP for different levels of NFC predicted by the same model are significantly different $(P<0.05$; data not shown).

Researchers have shown that ruminal $\mathrm{pH}$ was highly influenced by the dietary level of fermentable carbohydrates (Krause and Combes, 2003; Rustomo et al., 2006a,b). Furthermore, an investigation using the same studies (Table 1; data not shown) revealed that in vivo ruminal $\mathrm{pH}$ has a higher correlation with dietary NFC content $(\%, \mathrm{DM})$ than with total daily intake $(\mathrm{kg})$ of NFC, daily NDF intake (kg), NDF content (\%, DM), AV content ( $\mathrm{g}$ of $\mathrm{Ca} / \mathrm{kg}$ of $\mathrm{DM}$ ), or total AV intake ( $\mathrm{g}$ of $\mathrm{Ca} /$ d). Acidogenic values were calculated based on Rustomo et al. (2006c). Thus, data were pooled according to NFC content into low, moderate, and high. The effect of increasing NFC content on ruminal $\mathrm{pH}$ depression in the analysis across all studies translated into a shift of position of the $\mathrm{pH}$ curve toward a lower $\mathrm{pH}$ range, which in turn increased time below and AUC across all critical $\mathrm{pH}$ points. Depression of ruminal $\mathrm{pH}$ is also indicated by decrease in the $x$ coordinate of the inflection point (IP), $\operatorname{IP}(x)$, and slope of the curves. For example, the IP of the logistic for high NFC (Figure 3a) was [1.01, $729 ; \operatorname{IP}(x), \operatorname{IP}(y)]$. This indicated that the animals spent 729 min (approximately $12 \mathrm{~h}$ ) below $\mathrm{pH}$ 6.0. The model can also predict the amount of accumulated time spent below any given $\mathrm{pH}$; for example, the animals spent 475 and $283 \mathrm{~min} / \mathrm{d}$ below the critical $\mathrm{pH}$ points 5.8, and 5.6, respectively. In other words, a high level of NFC content $(>40 \%, \mathrm{DM})$ across trials with an IP of 1.01 indicated $\mathrm{pH}$ depression of $12.0,8.0$, and $4.7 \mathrm{~h}$ below $\mathrm{pH} 6.01$, 5.8 and 5.6, respectively. For moderate NFC content, the IP was $(1.17,7.16)$; therefore, it can be determined that animals spent 716, 284, and $148 \mathrm{~min} / \mathrm{d}$ below critical $\mathrm{pH}$ points of $6.17,5.8$, and 5.6, respectively. Studies combined in this analysis used either moderate or high NFC content diets to induce SARA. Hence, SARA could be defined as a daily drop of $\mathrm{pH}$ for 148 to $283 \mathrm{~min} / \mathrm{d}$ and 284 to $475 \mathrm{~min} / \mathrm{d}$ below 5.6 and 5.8, respectively. Alternatively, SARA could be defined as $\operatorname{IP}(x)$ of 1.01 to 1.17 , which is equivalent to spending approximately $12 \mathrm{~h}$ below a $\mathrm{pH}$ of 6.01 to 6.17 .

The slope of a $\mathrm{pH}$ curve was shown to be negatively correlated with dietary NFC. This can be explained by the differences in $\mathrm{pH}$ range covered during the day. High NFC content gave a greater drop in $\mathrm{pH}$ than low $\mathrm{NFC}$ and thus, a greater range of $\mathrm{pH}$ (i.e., 5.3 to 6.7 vs. 5.7 to 6.9 , respectively) and subsequently a smaller slope. Times below critical pH 6.0 and 5.6 have been widely reported by researchers because they provide significant biological information. However, model-derived values reported in Table 5 account for the study effect. Area under curve between $\mathrm{pH} 5$ and 5.6, AUC between $\mathrm{pH} 5$ and 6, and AUC between $\mathrm{pH} 5$ and 7.6 (total area) have been shown to have considerable potential in differentiating between curves. A greater value for area indicated a greater shift to the left namely, toward lower $\mathrm{pH}$ ranges.

The trial effect across all models and levels of NFC was significant. Seasonal variation in forage quality and carbohydrate fermentation might be the greatest contributor to this difference. On the other hand, study effect would contribute to a relatively greater numerical difference between model-predicted and observed values, hence a greater random error of prediction. This 
Table 3. Parameter estimates and other measures when models were fitted to low, moderate, and high NFC levels in the $\operatorname{diet}^{1}$

\begin{tabular}{|c|c|c|c|c|c|c|c|c|c|}
\hline \multirow[b]{2}{*}{$\mathrm{NFC}$} & \multirow[b]{2}{*}{ Item $^{2}$} & \multicolumn{2}{|c|}{ Logistic } & \multicolumn{2}{|c|}{ Richards } & \multicolumn{2}{|c|}{ Morgan } & \multicolumn{2}{|c|}{ Spline lines } \\
\hline & & Estimate & $\mathrm{SE}$ & Estimate & $\mathrm{SE}$ & Estimate & $\mathrm{SE}$ & Estimate & $\mathrm{SE}$ \\
\hline \multirow[t]{10}{*}{ Low } & $y_{0}$ & 7.2 & 0.9 & 26.5 & 4.2 & 71.3 & 11.4 & 68.4 & 11.0 \\
\hline & $y_{f}$ & 1,463 & 10.4 & 1,464 & 9.8 & 1,528 & 13.6 & 1,451 & 11.0 \\
\hline & $k$ & 4.2 & 0.1 & 5.9 & 0.4 & & & & \\
\hline & $n$ & & & 2.2 & 0.3 & 5.4 & 0.1 & & \\
\hline & $x_{h}$ & & & & & 1.3 & 0.0 & & \\
\hline & $x_{0}$ & & & & & & & 0.7 & 0.0 \\
\hline & $x_{f}$ & & & & & & & 1.9 & 0.0 \\
\hline & $\operatorname{Var} 1^{3}$ & 18,006 & 350 & 18,001 & 352 & 18,007 & 345 & 18,005 & 345 \\
\hline & $\operatorname{Var} 2^{4}$ & 330 & 72 & 300 & 64 & 342 & 77 & 326 & 72 \\
\hline & $\mathrm{BIC}^{5}$ & 24,440 & & 24,406 & & 24,516 & & 24,515 & \\
\hline \multirow[t]{10}{*}{ Moderate } & $y_{0}$ & 16.4 & 1.4 & 50.2 & 6.8 & 88.7 & 15.8 & 65.9 & 15.1 \\
\hline & $y_{f}$ & 1,431 & 8.7 & 1,457 & 10.6 & 1,526 & 16.7 & 1,416 & 14.8 \\
\hline & $k$ & 3.8 & 0.1 & 5.1 & 0.3 & & & & \\
\hline & $n$ & & & 2.1 & 0.2 & 4.5 & 0.1 & & \\
\hline & $x_{h}$ & & & & & 1.2 & 0.0 & & \\
\hline & $x_{0}$ & & & & & & & 0.5 & 0.0 \\
\hline & $x_{f}$ & & & & & & & 1.8 & 0.0 \\
\hline & Var1 & 22,006 & 262 & 22,003 & 262 & 22,023 & 258 & 22,006 & 259 \\
\hline & Var2 & 1,002 & 326 & 1,000 & 336 & 1,004 & 363 & 1,003 & 366 \\
\hline & BIC & 63,400 & & 63,356 & & 63,583 & & 63,548 & \\
\hline \multirow[t]{10}{*}{ High } & $y_{0}$ & 42.1 & 3.0 & 27.4 & 6.0 & 41.8 & 11.4 & 27.5 & $11.4^{\mathrm{NS}}$ \\
\hline & $y_{f}$ & 1,457 & 9.8 & 1,458 & 9.7 & 1,530 & 14.0 & 1,412 & 9.8 \\
\hline & $k$ & 3.5 & 0.1 & 3.1 & 0.2 & & & & \\
\hline & $n$ & & & 0.7 & 0.1 & 3.4 & 0.1 & & \\
\hline & $x_{h}$ & & & & & 1.0 & 0.0 & & \\
\hline & $x_{0}$ & & & & & & & 0.3 & 0.0 \\
\hline & $x_{f}$ & & & & & & & 1.7 & 0.0 \\
\hline & Var1 & 18,700 & 441 & 18,700 & 441 & 18,704 & 433 & 18,702 & 441 \\
\hline & Var2 & 250 & 45 & 251 & 46 & 303 & 60 & 280 & 54 \\
\hline & BIC & 28,953 & & 28,947 & & 29,007 & & 28,941 & \\
\hline
\end{tabular}

${ }^{1} \mathrm{NFC}$ level in the diet: low, 32 to $36 \%$; moderate, 37 to $39 \%$; and high, $>40 \% \mathrm{DM}$.

${ }^{2} y_{0}, y_{f}, x_{0}, x_{f}, x_{h}$, and $k$ (all $>0$ except $n>-1$ in the case of Richards) are parameters that define the scale and shape of the curves.

${ }^{3} \operatorname{Var} 1$ = variance $\left(\delta^{2}\right)$ of "error."

${ }^{4} \operatorname{Var} 2=$ variance $\left(\delta^{2}\right)$ of trial effects.

${ }^{5} \mathrm{BIC}=$ Bayesian information criteria.

${ }^{\mathrm{NS}} P>0.05$.

Table 4. Comparison of model performance using mean squared error of prediction (MSPE), root MSPE (RMSPE), and RMSPE as a percentage of the observed mean (\%RMSPE)

\begin{tabular}{llrccccc}
\hline & & & & & & \multicolumn{2}{c}{ Components of MSPE, \% } \\
\cline { 5 - 7 } NFC level $^{1}$ & Equation & MSPE & RMSPE & \%RMSPE & $\begin{array}{c}\text { Mean } \\
\text { bias }\end{array}$ & $\begin{array}{c}\text { Regression } \\
\text { bias }\end{array}$ & $\begin{array}{c}\text { Random } \\
\text { error }\end{array}$ \\
\hline \multirow{2}{*}{ Low } & Logistic & 334 & 18.3 & 2.5 & 0.23 & 3.45 & 96.32 \\
& Richards & 745 & 27.3 & 3.67 & 97.32 & 0.04 & 2.65 \\
& Morgan & 1,803 & 42.5 & 5.7 & 35.64 & 0.00 & 64.36 \\
\multirow{3}{*}{ Moderate } & Spline lines & 1,823 & 42.7 & 5.7 & 37.57 & 0.00 & 62.43 \\
& Logistic & 266 & 16.3 & 2.1 & 6.42 & 0.33 & 93.24 \\
& Richards & 1,773 & 42.1 & 5.3 & 97.96 & 0.02 & 1.98 \\
& Morgan & 2,347 & 48.5 & 6.2 & 50.69 & 0.17 & 49.14 \\
& Splighe lines & 1,526 & 39.1 & 5.0 & 36.17 & 0.00 & 68.83 \\
& Logistic & 691 & 26.3 & 3.1 & 45.57 & 2.14 & 52.23 \\
& Richards & 400 & 20.0 & 2.3 & 0.25 & 0.51 & 99.24 \\
& Morgan & 914 & 30.2 & 3.5 & 0.12 & 0.00 & 99.88 \\
& Spline lines & 342 & 18.5 & 2.2 & 0.46 & 0.00 & 99.54 \\
\hline
\end{tabular}

${ }^{1} \mathrm{NFC}$ level in the diet: low, 32 to $36 \%$; moderate, 37 to $39 \%$; and high, $>40 \% \mathrm{DM}$. 
Table 5. Biological values derived using each model for low, moderate, and high levels of dietary nonfiber carbohydrates (NFC, \% DM)

\begin{tabular}{|c|c|c|c|c|c|}
\hline \multirow[b]{2}{*}{$\mathrm{NFC} \mathrm{level}^{1}$} & \multirow[b]{2}{*}{ Item $^{2}$} & \multicolumn{4}{|c|}{ Equation } \\
\hline & & Logistic & Richards & Morgan & Spline lines \\
\hline \multirow{8}{*}{ Low } & $\mathrm{IP}\left(x^{*}\right), \mathrm{pH}-5$ & 1.28 & 1.36 & 1.21 & \\
\hline & $\mathrm{IP}\left(y^{*}\right), \mathrm{min} / \mathrm{d}$ & 732 & 864 & 666 & \\
\hline & Slope & 1,245 & 1,000 & 1,010 & 1,214 \\
\hline & Time $<\mathrm{pH} 5.6, \mathrm{~min} / \mathrm{d}$ & 83 & 132 & 93 & 68 \\
\hline & Time $<\mathrm{pH} 6.0, \mathrm{~min} / \mathrm{d}$ & 350 & 377 & 358 & 419 \\
\hline & $\mathrm{AUC}<\mathrm{pH} 5.6, \mathrm{pH} \min / \mathrm{d}$ & 19 & 40 & 46 & 42 \\
\hline & $\mathrm{AUC}<\mathrm{pH} 6.0, \mathrm{pH} \mathrm{min} / \mathrm{d}$ & 97 & 135 & 123 & 122 \\
\hline & $\mathrm{AUC}<\mathrm{pH} 7.6, \mathrm{pH} \mathrm{min} / \mathrm{d}$ & 1,941 & 2,017 & 2,004 & 2,010 \\
\hline \multirow{8}{*}{ Moderate } & $\mathrm{IP}(x), \mathrm{pH}-5$ & 1.17 & 1.25 & 1.07 & \\
\hline & $\mathrm{IP}(y), \mathrm{min} / \mathrm{d}$ & 716 & 853 & 648 & \\
\hline & Slope & 1,152 & 922 & 938 & 1,091 \\
\hline & Time $<\mathrm{pH} 5.6, \mathrm{~min} / \mathrm{d}$ & 148 & 212 & 153 & 135 \\
\hline & Time $<\mathrm{pH} 6.0, \mathrm{~min} / \mathrm{d}$ & 497 & 530 & 543 & 572 \\
\hline & $\mathrm{AUC}<\mathrm{pH} 5.6, \mathrm{pH} \mathrm{min} / \mathrm{d}$ & 37 & 69 & 61 & 41 \\
\hline & $\mathrm{AUC}<\mathrm{pH} 6.0, \mathrm{pH} \mathrm{min} / \mathrm{d}$ & 158 & 210 & 189 & 186 \\
\hline & $\mathrm{AUC}<\mathrm{pH} 7.6, \mathrm{pH} \mathrm{min} / \mathrm{d}$ & 2,058 & 2,181 & 2,154 & 2,129 \\
\hline \multirow{8}{*}{ High } & $\mathrm{IP}(x), \mathrm{pH}-5$ & 1.01 & 0.97 & 0.87 & \\
\hline & $\mathrm{IP}(y), \mathrm{min} / \mathrm{d}$ & 729 & 680 & 565 & \\
\hline & Slope & 1,098 & 875 & 889 & 1,001 \\
\hline & Time $<\mathrm{pH} 5.6, \mathrm{~min} / \mathrm{d}$ & 283 & 269 & 243 & 301 \\
\hline & Time $<\mathrm{pH} 6.0, \mathrm{~min} / \mathrm{d}$ & 718 & 717 & 737 & 702 \\
\hline & $\mathrm{AUC}<\mathrm{pH} 5.6, \mathrm{pH} \min / \mathrm{d}$ & 80 & 69 & 56 & 56 \\
\hline & $\mathrm{AUC}<\mathrm{pH} 6.0, \mathrm{pH} \mathrm{min} / \mathrm{d}$ & 275 & 262 & 251 & 258 \\
\hline & $\mathrm{AUC}<\mathrm{pH} 7.6, \mathrm{pH} \mathrm{min} / \mathrm{d}$ & 2,317 & 2,287 & 2,263 & 2,269 \\
\hline
\end{tabular}

${ }^{1} \mathrm{NFC}$ level in the diet: low, 32 to $36 \%$; moderate, 37 to $39 \%$; and high, $>40 \% \mathrm{DM}$.

${ }^{2}$ Items: $\operatorname{IP}\left(x^{*}, y^{*}\right)=$ inflection point of $\mathrm{pH}$ curve; slope of the $\mathrm{pH}$ curve (slope between $x_{1}$ and $x_{2}$ is $\Delta=$ $\left[y\left(x_{2}\right)-y\left(x_{1}\right)\right] /\left(x_{2}-x_{1}\right)$, where $x_{1}=x^{*}-0.4 \mathrm{pH}$ and $\left.x_{2}=x^{*}+0.4 \mathrm{pH}\right)$, where $\left(x^{*}, y^{*}\right)$ is the inflection point; predicted time below $\mathrm{pH} 5.6$ and 6.0 ( $\mathrm{min} / \mathrm{d}$ ); and area under the $\mathrm{pH}$ curve (AUC) between $\mathrm{pH} 5$ and $\mathrm{pH}$ 5.6, 6.0, and 7.6 (total area). Area under curve between 2 points, $x_{3}$ and $x_{3}+\delta$, is calculated as follows:

$$
\mathrm{AUC}=\int_{x_{3}}^{x_{3}+\delta} y(x) \mathrm{d} x \text {, where } x=\mathrm{pH}-5 .
$$

might explain the elevated random error encountered in this analysis. However, there is no known method to separate the effect of study or covariate when evaluating the performance of a given model.

In conclusion, the logistic can be used to describe curves constructed from continuous $\mathrm{pH}$ data. Values derived from this model, such as curve IP and slope, can be used to differentiate between $\mathrm{pH}$ curves. Time below critical $\mathrm{pH}$ cut-off points and area under the curve between any 2 given points can also be predicted. This approach accounts for study effect and could contribute greatly to our understanding of dietary effects on ruminal $\mathrm{pH}$.

\section{REFERENCES}

AlZahal, O., B. Rustomo, N. E. Odongo, T. F. Duffield, and B. W. McBride. 2007. Technical note: A system for continuous recording of ruminal $\mathrm{pH}$ in cattle. J. Anim. Sci. 85:213-217.

Bibby, J., and H. Toutenburg. 1977. Prediction and Improved Estimation in Linear Models. John Wiley \& Sons, Berlin, Germany.

Cottee, G., I. Kyriazakis, T. M. Widowski, M. I. Lindinger, J. P. Cant, T. F. Duffield, V. R. Osborne, and B. W. McBride. 2004. The effects of subacute ruminal acidosis on sodium bicarbonate-sup- plemented water intake for lactating dairy cows. J. Dairy Sci. 87:2248-2253.

Keunen, J. E., J. C. Plaizier, L. Kyriazakis, T. F. Duffield, T. M. Widowski, M. I. Lindinger, and B. W. McBride. 2002. Effects of a subacute ruminal acidosis model on the diet selection of dairy cows. J. Dairy Sci. 85:3304-3313.

Keunen, J. E., J. C. Plaizier, I. Kyriazakis, T. F. Duffield, T. M. Widowski, M. I. Lindinger, and B. W. McBride. 2003. Short communication: Effects of subacute ruminal acidosis on free-choice intake of sodium bicarbonate in lactating dairy cows. J. Dairy Sci. 86:954-957.

Krause, K. M., and D. K. Combs. 2003. Effects of particle size, forage, and grain fermentability on performance and ruminal $\mathrm{pH}$ in mid lactation cows. J. Dairy Sci. 86:1382-1397.

Krause, K. M., G. R. Oetzel, D. Kohn, D. Kuhn, and D. Frost. 2005. Continuous measurements of reticular and ruminal $\mathrm{pH}$ in dairy cows using wireless pH system. J. Dairy Sci. 88(Suppl. 1):132. (Abstr.)

Leonard, T., and J. S. J. Hsu. 2001. Bayesian Methods. Cambridge Univ. Press, Cambridge, United Kingdom.

Lin, L. I.-K. 1989. A concordance correlation coefficient to evaluate reproducibility. Biometrics 45:255-268.

Mitchell, P. L., and J. E. Sheehy. 1997. Comparison of prediction and observations to assess model performance: A method of empirical validation. Pages 437-451 in Application of Systems Approaches at the Field Level. M. J. Kropff, P. S. Teng, P. K. Aggarwal, J. Bouma, B. A. M. Bouman, J. W. Jones, and H. H. Van Laar, Ed. Kluwer Academic, Boston, MA. 
Mutsvangwa, T., J. P. Walton, J. C. Plaizier, T. F. Duffield, R. Bagg, P. Dick, G. Vessie, and B. W. McBride. 2002. Effects of a monensin controlled-release capsule or premix on attenuation of subacute ruminal acidosis in dairy cows. J. Dairy Sci. 85:3454-3461.

Nordlund, K. V., and E. F. Garrett. 1994. Rumenocentesis: A technique for collecting rumen fluid for the diagnosis of subacute rumen acidosis in dairy herds. Bovine Pract. 28:109-112.

Osborne, J. K., T. Mutsvangwa, O. AlZahal, T. F. Duffield, R. Bagg, P. Dick, G. Vessie, and B. W. McBride. 2004. Effects of monensin on ruminal forage degradability and total tract diet digestibility in lactating dairy cows during grain-induced subacute ruminal acidosis. J. Dairy Sci. 87:1840-1847.

Penner, G. P., K. A. Beauchemin, and T. Mutsvangwa. 2006. An evaluation of the accuracy and precision of a stand-alone submersible continuous ruminal pH measurement system. J. Dairy Sci. 89:2132-2140.

Rustomo, B., O. AlZahal, J. P. Cant, M. Z. Fan, T. F. Duffield, N. E. Odongo, and B. W. McBride. 2006a. Acidogenic value of feeds. II.
Effects of rumen acid load from feeds on dry mater intake, ruminal $\mathrm{pH}$, fiber degradability, and milk production in the lactating cow. Can. J. Anim. Sci. 86:119-126.

Rustomo, B., O. AlZahal, N. E. Odongo, T. F. Duffield, and B. W. McBride. 2006b. Effects of rumen acid-load from feed and forage particle size on ruminal $\mathrm{pH}$ and dry matter intake in the lactating dairy cow. J. Dairy Sci. 89:4758-4768.

Rustomo, B., J. P. Cant, M. Z. Fan, T. F. Duffield, N. E. Odongo, and B. W. McBride. 2006c. Acidogenic value of feeds. I. The relationship between the acidogenic value of feeds and in vitro ruminal $\mathrm{pH}$ changes. Can. J. Anim. Sci. 86:109-118.

SAS Institute. 2004. SAS/STAT User's Guide. Release 9.1. SAS Inst. Inc., Cary, NC.

Thornley, J. H. M., and J. France. 2007. Mathematical Models in Agriculture. 2nd ed. CABI Publishing, Wallingford, UK.

Wadhwa, D., N. F. G. Beck, L. P. Borgida, M. S. Dhanoa, and R. J. Dewhurst. 2001. Development of a simple in vitro assay for estimating net rumen acid load from diet ingredients. J. Dairy Sci. 84:1109-1117. 